\title{
Analysis of Anorthite Dissolution on the Submicrometer Scale
}

\author{
Margariete G. Malenda ${ }^{1}$, Heewon Jung ${ }^{2}$, Jeff Squier ${ }^{3}$, Brian Gorman ${ }^{4}$ Alexis Navarre-Sitchler ${ }^{1,2}$ \\ 1. Colorado School of Mines, Department of Geology and Geologic Engineering, Golden, USA. \\ 2. Colorado School of Mines, Hydrologic Sciences and Engineering, Golden, USA. \\ 3. Colorado School of Mines, Department of Physics, Golden, USA. \\ ${ }^{4 .}$ Colorado School of Mines, Department of Metallurgical and Materials Engineering, Golden, USA.
}

Dissolution reactions are critical to understanding various earth science and engineering processes: the release of contaminants into potentially potable groundwater, fluvial morphology development, and integrity of engineered structures such as well bores, dams and building foundations [1-3]. Yet there exist pervasive discrepancies between laboratory and field determined reaction rates [4]. Relationships between dissolution reactions across these scales can be described using Damköhler numbers, or ratios between mass transfer and chemical reaction rates (Eq. 1). This research investigates how variations in $\mathrm{pH}$ and Darcy flux $\left(\mathrm{U}_{\mathrm{x}}\right)$ affect the reaction rate $(\mathrm{R})$ and flow velocity respectively, during anorthite dissolution between the effective and local scale dissolution (Eq. 1). In situ analyses of anorthite dissolution (Eq. 2) focus on changes in solution chemistry at the effective area scale - the pore network - and at the local area scale - the interpore.

Flow experiments are conducted by injecting a fluid into $65 \times 25 \mu \mathrm{m}$ channels laser etched into a sample of anorthite [5] (Fig. 1). The idealized pore network is sealed with a clear layer of polydimethylsiloxane (PDMS), allowing fluid flow between the PDMS layer and the channel bottoms. An acidic solution ( $\mathrm{pH}$ $\sim 3.01$ ) is injected at one end of the channel network and fluid samples are collected at the outlet after having reacted with the anorthite channel walls. Effective reaction rates are calculated from the difference in $\mathrm{Ca}^{2+}, \mathrm{Al}^{3+}, \mathrm{SO}_{2(\mathrm{aq})}$, and $\mathrm{H}^{+}$concentrations between inlet and outlet fluids. Flow rate is determined from time-lapse images of $2 \mu \mathrm{m}$ diameter Fluoro-Max Red fluorescent beads using an Olympus BX51 fluorescence microscope with a $0.02 \mathrm{sec}$ exposure time.

To measure reactions on the local or inter-pore scale, we must capture information on micron to nanometer scale processes. Using two-photon excitation fluorescence imaging (TPEF) with a ytterbium femtosecond laser developed at Colorado School of Mines, spatial frequency modulation for imaging (SPIFI) will be tested to detect $\mathrm{Ca}^{2+}$ release on the micron to submicron scale. Tests will entail adding a fluorescing $\mathrm{Ca}^{2+}$ indicator to the flow solution and conducting laser imaging during flow through experiments to capture $\mathrm{Ca}^{2+}$ release during dissolution. SPIFI has been used with TPEF and with second-harmonic generation (SHG) to image inorganic and biological samples [6,7]. However, this would be the first time in-situ geochemical dissolution has been captured with SPIFI.

Electron microscopy is used to characterize and select appropriate mineral samples (ESEM and EDS), map regions of potential sample damage during laser ablation for subsequent removal (TEM) (Fig. 2), and elemental mapping of channel cross sections before and after flow through experiments (STEM).

Anorthite specimen with etched flow-through channels have been used to induce and capture effective mineral dissolution. Continued work will involve varying the acidity and velocity of flow-through solutions to assess the dependence of anorthite dissolution on these two variables. Observations of solution chemistry on the local and effective scales will help us to understand how these dependencies 
vary for dissolution rates at the local and effective scales [8].

References:

[1] P. Cao, Z. T. Karpyn, and L. Li, Water Resources Research 49 (2013), p. 4465.

[2] D. C. Craft, R. M. Pearson, and D. Hurcomb, Water Operation and Maintenance Bulletin 224 (2008), p. 1.

[3] M. P. Luong, International Conference on Case Histories in Geotechnical Engineering (1984) p. 26.

[4] J. I. Drever, K. M. Murphy, and D. W. Clow, Mineralogical Magazine 58A (1994), p. 239.

[5] H. Jung et al, Geological Society of America Annual Meeting (2016) p. 331.

[6] J. J. Field, et al, Proceedings of the National Academy of Sciences 113 (2016), p. 6605.

[7] R. Grange et al, Biomedical Optics Express, 2 (2011), p. 2532.

[8] This material based in part on work supported by the National Science Foundation under Award No. EAR-1554502.

$\mathbf{D a}_{\overline{\mathrm{i}}}=\frac{\mathbf{A}_{\mathrm{b}} \mathbf{R x}}{\mathbf{U}_{\mathrm{x}} \mathrm{C}_{\mathrm{eq}, 1}}$

Equation 1. The Damköhler equation relating advective transport in terms of the mineral surface area $\left(A_{b}\right)$, the dissolution rate $(R)$, and the distance of the reaction path length $(x)$ to reaction rates in terms of the Darcy flux $\left(\mathrm{U}_{\mathrm{x}}\right)$, and the equilibrium concentration $\left(\mathrm{C}_{\mathrm{eq}, \mathrm{x}}\right)$.

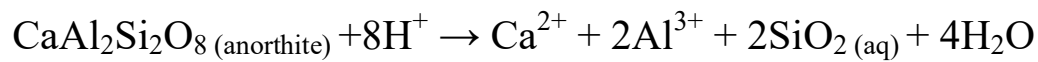

Equation 2. Anorthite dissolution reaction of interest.

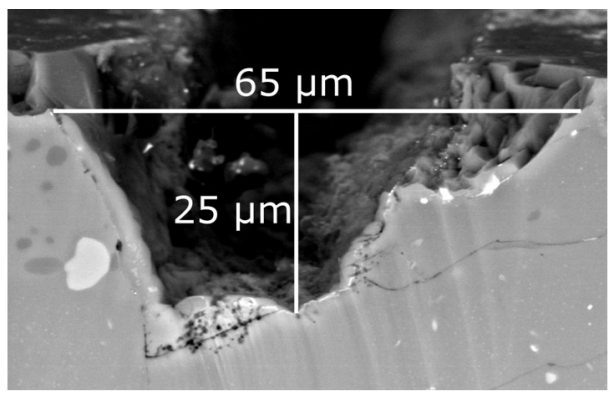

Figure 1. ESEM image of channel cross section.

a.
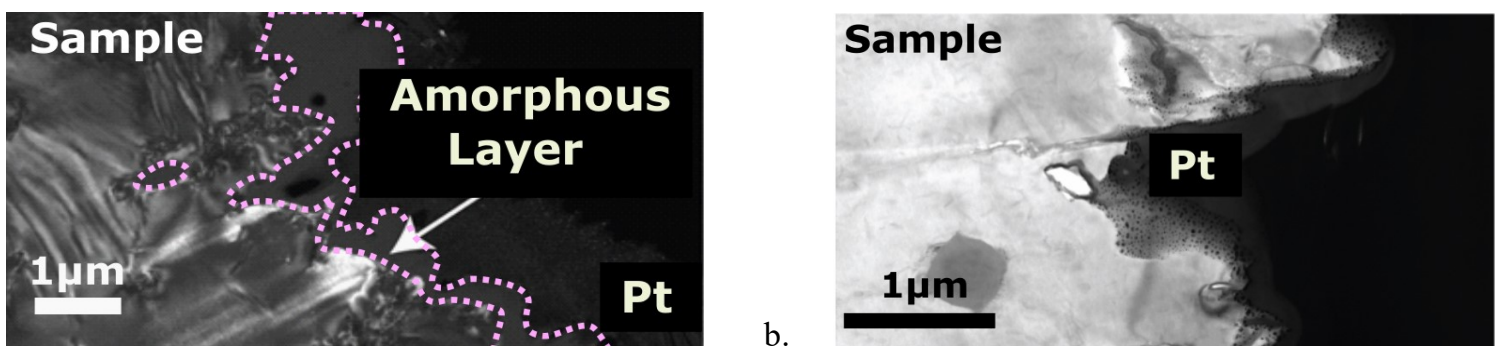

Figure 2. TEM images of a) the amorphous layer damage and b) the anorthite sample after removal of the amorphous layer leaving anorthite with a layer of platinum deposited during sample preparation. 